\title{
Challenges and opportunities in addressing social determinants of child health in Cambodia: perspectives and experience of frontline providers in two health districts
}

\author{
Keovathanak Khim ${ }^{1,2}$ (D) Anne Andermann ${ }^{2,3}$ \\ Received: 1 December 2019 / Accepted: 25 October 2020 / Published online: 20 January 2021 \\ (C) The Canadian Public Health Association 2021
}

\begin{abstract}
Objectives Other forces related to socio-economic and cultural factors, besides biomedical and behavioural fields, also influence health but receive little attention in health research. This study aims to illuminate social determinants of health and to identify challenges and opportunities in addressing social determinants of child health $(\mathrm{SDCH})$ in rural Cambodia.

Methods This is a qualitative study based on interviews of frontline primary health care providers, health officials, local authorities and community volunteers in two health districts in Cambodia. The data were supplemented by secondary data on different aspects of the districts and Cambodia.

Results Poverty, lack of basic commodities and adverse social conditions remained problems for population health. While access to health services was considered adequate, households and communities had several major risk exposures. Challenges in addressing SDCH were the high prevalence of social and household adverse conditions, and the lack of training of providers, of information about social services, of effective coordination and of trust in public services. Opportunities were present, including social services being existent albeit poor functioning, the traditional practice of social inquiry, existing frontline providers being open to further information and training, existing subnational coordination bodies at district and provincial levels, and use of evidence in planning and resource allocation.

Conclusion Addressing SDCH requires broad and coordinated efforts of stakeholders from multiple sectors. Among the prerequisites are to leverage the existing structures and mechanisms, training primary health care providers and providing them with adequate information about local resources and available supports. Improving social care services and infrastructures requires strong coordination, planning and adequate resource allocation.
\end{abstract}

\section{Résumé}

Objectifs D'autres forces liées aux facteurs socio-économiques et culturels, en plus des domaines biomédicaux et comportementaux, influencent également la santé mais reçoivent peu d'attention dans la recherche en santé. Cette étude vise à éclairer les déterminants sociaux de la santé et à identifier les défis et les opportunités pour aborder les déterminants sociaux de la santé infantile (SDCH) dans les régions rurales du Cambodge.

At the time of study, Keovathanak Khim was a Postdoctoral Fellow in the Department of Family Medicine at McGill University, Montreal, Canada. He was formerly Head of Public Health Unit at University of Health Sciences, Cambodia and is currently Monitoring, Evaluation and Learning Manager of the ACCESS Program in Cambodia.

Keovathanak Khim

kkvathanak@gmail.com

1 Public Health Department, University of Health Sciences, 73, Monivong Blvd., Khan Daun Penh, Phnom Penh, Cambodia

2 Department of Family Medicine, McGill University, Montreal, Quebec, Canada

3 School of Population and Global Health, McGill University, Montreal, Quebec, Canada 
Méthodes Il s'agit d'une étude qualitative basée sur des entretiens avec des prestataires de soins de santé primaire de première ligne, des responsables de la santé, des autorités locales et des volontaires communautaires dans deux districts de santé au Cambodge. Les données ont été complétées par des données secondaires sur différents aspects des districts et du Cambodge.

Résultats La pauvreté, le manque de produits de base et les conditions sociales défavorables restent des problèmes pour la santé de la population. Bienque l'accès aux services de santé est considéré suffisant, les ménages et les communautés sont exposés à plusieurs risques majeurs. Les défis liés à la lutte contre la SDCH étaient la prévalence élevée de conditions sociales et domestiques défavorables, ainsi que le manque de formation des prestataires, d'informations sur les services sociaux, de coordination efficace et de confiance dans les services publics. Des opportunités étaient présentes, y compris des services sociaux existants bienque fonctionnant mal, la pratique traditionnelle de l'enquête sociale, les prestataires de première ligne existants étant disposés à encore d'informations et de formation, les organes de coordination sous-nationaux existants au niveau des districts et des provinces, et l'utilisation des preuves dans la planification et l'allocation des ressources.

Conclusion Aborder la SDCH nécessite des efforts larges et coordonnés des parties prenantes de plusieurs secteurs. Parmi les conditions préalables, il faut tirer parti des structures et mécanismes existants, former les prestataires de soins de santé primaire et leur fournir des informations adéquates sur les ressources locales et soutiens disponibles. L'amélioration des services et des infrastructures de protection sociale nécessite une coordination, une planification et une allocation adéquate des ressources.

Keywords Social determinants of health $\cdot$ Cambodia $\cdot$ Community health $\cdot$ Service referral $\cdot$ Social care

Mots-clés Déterminants sociaux de la santé $\cdot$ Cambodge $\cdot$ santé communautaire $\cdot$ référence de service $\cdot$ la protection sociale

\section{Introduction}

It has long been acknowledged that factors influencing individual and population health are many (Marmot and Wilkinson 2000), aside from biomedical and behavioural conditions of individuals (Davey Smith and Ebrahim 2001). Different schools of thought explain various pathways and layers of how political, social and economic factors influence risk exposure, distribution of resources for healthcare, and thus individual and population health (Krieger 2001; Wilson 1983).

According to the World Health Organization (WHO), social determinants of health (SDH) are defined as "the conditions in which people are born, grow, live, work and age; these circumstances are shaped by the distribution of money, power and resources at global, national and local levels" (CSDH 2008). According to the Ottawa Charter for Health Promotion, peace, shelter, education, food, income, a stable ecosystem, sustainable justice and equity were counted as prerequisites for health (World Health Organization 1986). Other factors included as contributors to health are agriculture and food production, education, work environment, employment, water and sanitation, healthcare services, and housing (Dahlgren and Whitehead 1992). All of these are reflected in shared commonalities documented in an increasing number of policy documents of different countries, most often high-income countries, outlining their approaches to SDH. There is also growing consensus around the key determinants of health, including social exclusion, unemployment and employment security (Raphael 2004).

Research has identified different approaches to SDH and various ways to explain changing health. Three approachesmaterialist, neomaterialist and psychosocial comparisonexplain how conditions of living and wealth of a nation
(Navarro 1977), social infrastructures, the distribution of these infrastructures (Lynch et al. 2000), and the effect of the differences in these translated into hierarchies and how social distances define one's social standing and perceptions of communal structures (Kawachi and Kennedy 2002).

Many social factors could affect health and they are often considered beyond the mandates of health authorities; therefore, interventions to improve health require distributed leadership, strong multisectoral collaboration and coordination (Rasanathan et al. 2017); these are lacking and had seen limited applications in low- and middle-income countries (Bennett et al. 2018).

Inequity in health status is a manifestation of SDH. It is primarily the result of disparity in socio-economic conditions, political decisions and/or cultural factors (Friel et al. 2012). Gaps in health outcomes occur along the line of urban/rural split, by income group, level of education and type of occupation, ethnicity and so forth. For example, urban well-off populations could benefit more from availability of and access to social infrastructures and services while the urban poor may have restricted access to them due to costs and affordability issues, whereas rural populations likely lack social services and infrastructures as development concentrates more in urban areas (Saha and Gerdtham 2013). Gender-biased social norms have a role in facilitating gender-based violence (GBV) and prejudice which have become a public health issue in many countries and are associated with adverse maternal and child health outcomes (Krantz 2002; Hill et al. 2016; Hooker et al. 2012; Mohammad et al. 2015; Ziaei et al. 2014).

Among the many recommendations from the WHO's Commission on SDH, improving equity in child health means ensuring equitable early childhood development - including physical, social/emotional and language/cognitive 
dimensions, all of which have a determining influence on the subsequent life changes and health through skills development, education and occupational opportunities (CSDH 2008). Investment in the early years - including perinatal care and care during the first 8 years of life; good nutrition; safe, healthy, supporting, caring and responsive living environments and pre-school and school environments-provides the best returns in health outcomes (Bell et al. 2018).

Studies on SDH suggest that there are ways health providers can help to address social problems faced by their clients. One way health workers can do this is by asking clients about the social challenges they face in the community (Naz et al. 2016) and assisting them in navigating and accessing social services and other local support resources (Andermann 2016). Training health workers and providing them with the necessary information and skills for social inquiries is essential (Kuo et al. 2011). With knowledge about broader health system functions and interplays of non-health sectoral issues having impacts on health outcomes, health workers are more likely to integrate social inquiry as part of their practices (National Academies of Sciences 2016). The training has to be appropriate to capacity, the health system context and culture. Community workers, volunteers and local authorities are also among the first contact people in the community and can serve to facilitate access to and referral for services, and including them as important stakeholders in SDH intervention is necessary (Le et al. 2018). Despite the fact that population health is so intertwined with socio-economic, political and cultural conditions, studies on SDH in low- and middle-income countries have been limited and often neglected.

This is a Cambodian case study to illustrate the important roles of frontline service providers in addressing SDH and to provide an understanding about the current practices by the frontline primary health care providers in this field. The study could be useful for policy-making to improve health workers' and service providers' practices in social inquiry. In Cambodia primary healthcare facilities, community volunteers and commune officials are frontline service delivery points closest to people and see all sorts of health and social problems.

This study attempts to answer the following questions:

1. What are the major social determinants of child health $(\mathrm{SDCH})$ in rural districts in Cambodia?

2. What are the challenges and opportunities for frontline providers in addressing the social issues and problems?

Some background on Cambodia and its health system may be useful for understanding why this study is important. Cambodia started to rebuild the health system after over two decades of civil wars and social unrest in the 1970s and 1980s. Over the past two decades, significant improvements in population health and health service provision were made; these occurred amid consistent economic growth and progressive social policies (Table 1). The liberalization of the market economy and private sector growth contributed to consistent double-digit economic growth over several years in the 2000s and 2010s; and the country has recently been upgraded to a lower-middle-income country (World Bank 2019).

Despite the gains, inequity in health status and access to health services has been long known in Cambodia and is associated with urban-rural and economic divides. Cambodian children in rural areas are three times more likely to die than those in urban areas (under 5 mortality: rural area 52 versus urban area 18 per 1000 live births); this could be explained in part by economic status and mother's education, as well as access to health services. Children in the highest economic quintile have lower mortality rate than those in the lowest quintile ( 16 versus 62 per 1000 live births); children born to a mother with no education have higher mortality rate than those born to a mother with secondary education or higher (63 versus 26 per 1000 live births) (NIS. DGH. ICF International 2015). Mothers are the major
Table 1 Progress in socioeconomic and health sectors, 1990-2014, Cambodia

\begin{tabular}{llll}
\hline Indicator & $1990^{*}$ & 2000 & 2014 \\
\hline Population (million) & 8.9 & 12 & 14.5 \\
Poverty rate (\% of population)^ $^{\wedge}$ & $\mathrm{n} / \mathrm{a}$ & 50 & 18 \\
Life expectancy (years, both male and female) $^{\wedge}$ & 53 & 58 & 68 \\
GDP (USD)^ & 254 & 302 & 1093 \\
Maternal mortality ratio (per 100,000 live births) & 1020 & 437 & 170 \\
Infant mortality (both sexes) (per 1000 live births) & $\mathrm{n} / \mathrm{a}$ & 95 \\
Under 5 mortality (both sexes) (per 1000 live births) & 127 & 124 & 35 \\
HIV prevalence (\% among general population)^ & 0.1 & 1.6 & 0.6 \\
Tuberculosis prevalence (per 100,000 population) & $\mathrm{n} / \mathrm{a}$ & 1619 & 817 \\
Number of hospitals** & $\mathrm{n} / \mathrm{a}$ & $<40$ & 97 \\
Number of health centres** & $\mathrm{n} / \mathrm{a}$ & $<400$ & 1105 \\
\hline
\end{tabular}

CDHS data (except when otherwise indicated); $n / a$, data not available; GDP (USD), gross domestic product (US dollars); * Maternal mortality, 1990-2015, Cambodia: https:/www.who.int/gho/maternal health/countries/khm. pdf; ** MOH Achievement report 2017; ${ }^{\wedge}$ World Bank data (WB 2019) 
sources of care of young children, and their knowledge and practices in caring for young children are essential for good care. Problems of social and health inequity are also prevalent in urban areas. Poor urban Cambodians are disadvantaged because of their low education, lack of knowledge about health and healthcare, poor living conditions exposing them to risks and diseases, and high costs of living and access to healthcare (Soeung et al. 2012).

Various schemes have been implemented in the country to address inequitable access to health services and disparity in health status. Health equity fund schemes to assist the poor and vulnerable, usually rural populations, to have free access to publicly funded health services were piloted in the late 1990s, scaled up in the 2000s and 2010s, and currently integrated into the health system (Annear et al. 2019; Flores et al. 2011; Noirhomme et al. 2007). Maternal health voucher schemes were implemented in selected provinces to address disparity in maternal health status (Ir et al. 2010; Van Damme et al. 2008). Different forms of performance-based contracting to address the quality of service provision have been implemented in various forms in the last 25 years and have now been integrated in the health system (Khim and Annear 2013; Khim et al. 2017).

Beyond the health sector, Cambodia has some positive experience with implementation of multisectoral responses to many social and health problems, notably the first successful response to the HIV/AIDS epidemic during the early 2000s (Phalla et al. 1998), thanks to strong coordinated multisectoral responses involving other sectors besides health, including local authorities, law enforcement, and women's affairs. Cambodia was able to reduce the prevalence of HIV transmission among the general population aged 15-49 from a peak of $2.8 \%$ in 1998 to $0.6 \%$ in 2006 (Charles 2006). This lesson of multisectoral response has been replicated in addressing other problems, such as violence against women, and social and disability inclusion. The National Action Plan to eliminate Violence Against Women (NAPVAW) (MOWA 2014) and the National Disability Strategic Plan (MOSVY 2014) are examples of national strategic plans with multisectoral coordination platforms at the national and subnational levels. In addressing GBV, subnational GBV working groups composed of officials from several sectors, i.e., justice, police, social affairs, and health, are established and tasked to resolve and coordinate services for GBV clients (Coffey 2017; MOH and MOWA 2016). Similarly, in the disability area, cross-sectoral collaborations on interventions in public domains improve policy, coordination and access to rehabilitation services and improve the social and economic conditions of people with disabilities, what is generally called disability inclusion (Unicef, UNDP, \& WHO 2018). Subnational mechanisms such as the Implementation of Social Accountability Framework and Commune Investment Plan have been leveraged to ensure adequate multisectoral coordination in addressing community social problems, most notably in education, health and social welfare sectors (NCDD 2015).

\section{Theoretical foundations of the study}

Considering the wide range of factors influencing individual and population health in various pathways, this study is inclusive in its theoretical approach employing a combination of materialist, neomaterialist, psychosocial comparison and behavioural explanations. The materialist approach to SDH considers conditions of living such as housing, food, income, and access to commodities as the primary factors influencing health. The neomaterialist approach looks at social infrastructures, such as social and public services for health, education or child care as important factors affecting health. Examples of social infrastructures include public water distribution networks, public health services, safety and security, and exposures to household and communal adverse conditions, such as second-hand tobacco smoke, drug use, and violence. The psychosocial comparison approach explains the sentiment and perception of one's social standing and the social experiences which could be linked to mental and psychological conditions, such as isolation, maltreatment and discrimination. The behavioural dimension looks at knowledge about social services which influences provider's practices. These approaches will guide the thematic focuses of this study and the development of the clinical support tool.

\section{Methods and data}

Attempts were made to adhere to the guidelines on qualitative research in the design, implementation and reporting of the study (Tong et al. 2007). This is a case study based on data from two rural districts - Cheungprey and Prey Chhor in Kampong Cham province. Participants of the study were frontline providers of health and social care and were purposively selected: 32 primary health care providers from 16 health facilities, three provincial and district health officials, two commune council members and two village women volunteers in the two health districts. None of the officials declined the request for an interview. The qualitative data were supplemented by secondary data related to aspects of socioeconomic and poverty conditions in the districts.

In Cambodia, primary health care providers are predominantly midwives and, in these study districts, represented over $70 \%$ of the health care providers. They are tasked to provide maternal and child health services, e.g., family planning, perinatal care, newborn delivery and care at the health facilities, health education and vaccination, and some outreach activities. The provincial officials, health district officials, the commune council members and village volunteers were included because they were familiar with the contexts and social and health problems in the districts and province. Commune councils are elected community members and are involved in all 
aspects of community development. Village volunteers are usually recognized community members active in and trained in various areas of community development.

The midwives were invited to their respective health district office, informed about the study on newborn care and the qualitative in-depth interviews related to social and community issues. They were asked for consent before participating in the study. The brief self-administered survey covered questions related to demographics, duration of clinical practice, practice population, types of social challenges encountered in clinical care, and so forth, and this was followed by administering a semi-structured in-depth interview guide on provider's experience with social barriers to health, perceptions of the role of primary health care providers and experience with referral for local support services.

All the interviews were conducted face to face. The interviews with the health district officials were focused on factors within community and households which affect child health, the roles of health providers and what they actually do in response to these factors. The interviews with local authorities focused on their perceptions about factors in community and households which may affect health and their roles in addressing them.

The questions in the survey and interview guide were developed, adapting from the CLEAR Toolkit of McGill University (Andermann 2016; https://www.mcgill.ca/clear/ download\#Kmer) and contained items reflecting the theoretical approaches described earlier related to material wealth, social infrastructures, and psychosocial aspects which are relevant to the issues of mental and psychological health and well-being, which influence early childhood development. These question items are related to different aspects of SDH and reflect challenges and opportunities in the current practices and management of SDH by primary health care providers.

The interviews were between 30 and $45 \mathrm{~min}$ in duration and were voice recorded along with note-taking. The data were transcribed verbatim. No software was used to assist the analysis. Content analysis was conducted by thematic area identified in advance of the fieldwork and corresponding to the research questions. Quotations with respondent codes were presented to provide support and illustrate the themes.

All participants of the study gave consent before joining the interviews. Field data were collected in September and October 2018. The study was approved by Cambodia's National Ethics Committee for Health Research and the McGill Institutional Review Board.

\section{Results}

The results of the study are presented in the following ordercharacteristics of health providers in the two districts, SDCH, and challenges and opportunities in addressing SDCH. Quotations from interviews with local authorities, primary health care providers and health officials are used to illustrate the main themes.

\section{Health provider's characteristics}

A total of 31 primary health care providers of the planned 32 participated in the self-administered survey and face-to-face in-depth interview. All the health providers were female, mean age 39 years and mean job tenure at the current facilities 15 years (minimum 1.5 years and maximum 40 years). A total of 26 of 31 providers completed 3 to 4 years of midwifery training, the rest had 2 years of midwifery training.

\section{Social determinants of child health in the two districts}

Table 2 shows data and information related to social and demographic aspects of the two districts based on the districts' 3-year revolving plans made in 2019 and the data from Cambodia Socio-Economic Survey 2017 to give perspectives of contexts. These data are suggestive of high presence of SDCH in the districts, with high poverty rates, high number of orphaned children and of people with disability and of migrant populations. Both districts are located along the National Road 6, Northeast of the capital city of Phnom Penh and primarily treated as semi-rural districts, with large concentrations of population in the district towns. The districts are lower than the Cambodia average (22\%) in terms of the proportion of households headed by women (Prey Chhor 15\%; Cheung Prey 20\%), but they are close to the Cambodia average in terms of the proportion of households with electricity, with more than three quarters of households connected to the public electricity grid.

The districts are above the Cambodia average in terms of access to safe water, with $80 \%$ and above of households in the districts connected to public water distribution systems. However, sanitation in Cheung Prey was problematic as only $60 \%$ of households had their own latrine, lower than the country average $(76 \%)$. Both districts were ahead of the country in terms of literacy, with almost all population aged $18-45$ being literate, higher than the country average (82\%).

Both districts had a significant proportion of migrant populations, close to a quarter of the total in Cheung Prey. Both districts had high need for social care in terms of orphaned children, persons living with disabilities, and families experiencing domestic violence. Poverty remained a problem, much more in Cheung Prey, with a higher poverty rate (19\%) than Prey Chhor and the Cambodia average (13.5\%).

In terms of mechanisms to address violence and maintain social order, the whole province of Kampong Cham and both districts included in the study had coordinating bodies, such as the GBV violence working group, the Women and Children Committee, and the HIV/AIDS response group. Officials from different sectors, for example, 
Table 2 Characteristics and social services in Prey Chhor and Cheung Prey districts and in Cambodia overall

\begin{tabular}{|c|c|c|c|}
\hline Social and community characteristics & Prey Chhor* & $\begin{array}{l}\text { Cheung } \\
\text { Prey* }\end{array}$ & Cambodia** \\
\hline Total population ( $\%$ female) & $\begin{array}{l}152,974 \\
(50.8 \%)\end{array}$ & $\begin{array}{l}101,219 \\
\quad(50.9 \%)\end{array}$ & $15,848,000$ \\
\hline Percentage of people aged less than 18 & $27 \%$ & $36 \%$ & \\
\hline Distance from the capital city (Phnom Penh) (km) & 90 & 60 & - \\
\hline Number of families & 44,306 & 26,848 & $3,438,000$ \\
\hline Percentage of female-headed households ( $\%$ of total) & $15 \%$ & $20.4 \%$ & $22 \%$ \\
\hline $\begin{array}{l}\text { Percentage of families whose primary occupation is } \\
\text { agriculture }\end{array}$ & $70 \%$ & $66.2 \%$ & - \\
\hline Percentage of houses with electricity & $85 \%$ & $76 \%$ & $78 \%$ \\
\hline $\begin{array}{l}\text { Percentage of families who have safe water sources during } \\
\text { the dry season }\end{array}$ & $98 \%$ & $79.5 \%$ & $65 \%$ \\
\hline Percentage of families who have their own latrine & $88 \%$ & $59.2 \%$ & $76 \%$ \\
\hline Number of families with domestic violence & 151 & 111 & - \\
\hline $\begin{array}{l}\text { Percentage of migrant population (domestic and } \\
\text { international) }\end{array}$ & $17 \%$ & $23.4 \%$ & - \\
\hline Percentage of people literate aged $18-45$ & $96 \%$ & $94 \%$ & $82 \%$ \\
\hline Number of orphaned/abandoned children & 45 & 66 & - \\
\hline Number of disabled people (\% unable to earn income) & $1100(44 \%)$ & $137(30 \%)$ & - \\
\hline Poverty rate $(\%)$ & $11 \%$ & $19 \%$ & $13.5 \%$ \\
\hline Number of deaths due to traffic accidents & 42 & 30 & - \\
\hline Percentage of children aged 9-12 months fully immunized & $99.5 \%$ & $98 \%$ & $97 \%$ \\
\hline Number of referral hospitals $(R H)$ & 1 & 1 & 123 \\
\hline Number of medical doctors & 5 & 8 & 3400 \\
\hline Number of health centres $(H C)$ & 11 & 7 & 1205 \\
\hline Number of midwives at $\mathrm{HCs}$ & 30 & 20 & 6800 \\
\hline Number of nurses at HCs & 36 & 17 & 10,900 \\
\hline
\end{tabular}

*Source: district 3-year revolving plans, 2019; **Cambodia Socio-Economic Survey 2017; Italicized entrybased on Health Management Information System of MOH 2017 in the case of the GBV working group, included representatives from justice, police force, and health and social affairs, who participate in these bodies.

In the health sector, the districts had low numbers of health staff. None of the health centres in the two districts had a medical doctor, a situation similar to that in the rest of the country. Health centres are the frontline primary health care facilities and are staffed predominantly by midwives. Only a small number of health centres annexed to referral hospitals are staffed with medical doctors or medical assistants. Even with that, the ratio of health provider (nurse or midwife) to population is low-approximately one health provider per 2100 population; and the ratio of medical doctor to population is far lower.

Data from the brief self-administered demographic survey and in-depth interviews among the primary health care providers included in the study portrayed a still gloomier picture of the social and health situations in the districts. Major issues identified were related to: lack of knowledge of child care, of safe places for children, of safe drinking water, of adequate food, and of income and employment; and exposure to second-hand tobacco smoke. Alcohol use, drug use, feeling of insecurity, isolation and discrimination were still issues among a small number of households in the districts although they were not prominent and often unspoken because of their stigmatizing nature.

The lack of knowledge about nutrition and child feeding was commonly cited. A health provider (\#5), 32 years of age said, "Many elderly who look after children lack knowledge about nutrition and child feeding and feed children mostly the same certain types of food they like, e.g., fish paste, fermented fish; therefore, many children become malnourished."

Over half of health providers said women or caretakers had inadequate knowledge about child care. Interviewed health district officials and local authority officials indicated that knowledge about child care in the community remained limited. "These days young mothers tend to have good knowledge about health and child care, but many of them are away working, mostly in garment factories, so many mothers leave children in the care of grandparents or elderly relatives who do not have knowledge about child care and feeding. The elderly tend to follow the old habits 
and practices, for example, not properly washing hands or not hygienically storing milk for babies, feeding young children with the food they liked which may not be good for young children" (A health district official, \#33).

Health providers said food shortage in the community did occur on an occasional basis. A number of health providers interviewed said it happened to a number of households during the planting seasons. Local authorities said a few households rated as poverty level 1 lived in abject poverty, without land or with intermittent labour jobs, resorting to begging; some received assistance from Cambodian Red Cross or hand-outs from neighbours.

Related to care for the safety of children, there is a convergent view among health providers and local authorities that some households lacked a safe place for children. They said often children were seen running around in the bushes or on the road, climbing trees, or playing near ponds, thus exposing themselves to a variety of risks. They said houses and living facilities were not built with child protection in mind; for example, ponds and stairs were not barricaded to prevent small children from falling in or down; water is stored in deep jars and could be a drowning safety issue for small children; bushes surrounding the house are sources of mosquitos and other biting insects. In the words of a health provider (\#21), 40 years of age, "When speaking about children safety, we have many problems, for example, infants are not adequately protected from heat and cold when parents bring them to the field, ...small children are left roaming around in bushes and near water holes."

Access to clean drinking water was still a major challenge for remote communities. Almost half of the health providers said households in the district community lacked adequate water for washing and for drinking almost regularly, especially during the dry season for communities without wells. Interviewed local authorities said when wells and ponds dry up, people resort to buying bottled waters and some households cannot afford to do this. According to a health provider (\#26), "Lack of water is often the main issue for remote villages in the dry season; they are forced to use whatever water is available in ponds, sharing with animals, the water is dirty and the source of diseases."

In relation to tobacco use and exposure to second-hand smoke, most of the health providers said children continue to be exposed to tobacco use and second-hand smoke in many households. "Smoking is so prevalent in villages, regardless of places - inside or outside homes," according to a community volunteer (\#36), 30 years of age from $\mathrm{O}^{\prime}$ Tanov village in Prey Chhor district.

This is further corroborated by the local authority, who says that smoking is still common in the community, though the prevalence decreased compared with 5 years ago. More people knew about the bad consequences of smoking. Many men had quit, however many others continue to smoke. Another worrying trend is that of young people smoking (i.e., those in their late teen years), according to a village woman volunteer.

A small number of health providers met or knew mothers of young children whose family had a problem with drug use. The commune authority in Cheung Prey district (\#35) said, "Drug problem is rare but increasing. It is rare because it is difficult to monitor as people hide themselves when using drugs." This is echoed by the health officials who cited an increase in drug use in the community.

A small number of providers said they met pregnant women and mothers of young children who reported alcohol problems in the households. Health officials and local authorities agreed that people drink less often but drink more heavily each time, especially during long holiday seasons such as Khmer or Chinese New Year and during festivals. They drink less often because they have to work the next day; many men are now employed. Heavy and regular drinkers are fewer. "Alcohol use is less in terms of frequency, but more in terms of volume consumed, when people have long time to relax and meet relatives. And children are around the drinking table, some of them more or less follow [laughing]," says a community volunteer (\#36), 28 years of age.

About a third of health providers said they occasionally met pregnant women and mothers of young children who reported they experienced violence or domestic abuse in the households. The violence often occurred in the form of verbal confrontation and swearing; physical fights were rare. According to health officials and local authorities, domestic violence had decreased quite significantly in the last 5 years, due to interventions by the local authorities. They arrested perpetrators and had them sign a pledge not to repeat the act. It recurred only occasionally, often among families of heavy drinkers.

Lack of income and unemployment are prevalent among rural households, and constitute the main source of poverty. The majority of health providers said they often met pregnant women and mothers of young children whose household had no or inadequate income. Often the households had no land and earned income through physical labour jobs. The commune council members agreed that incomes from such labour jobs were too small to sustain the livelihood of these families. Some were forced to scavenge for junk items they could sell, such as waste plastic bottles, and make $\$ 2.50$ a day at best. "It's all about making enough money for the family; without land and knowledge, some families rely on labour jobs which are not always available, like carrying soil or digging ponds," says a health provider (\#18), 36 years of age, from Prey Chhor district.

Discrimination within rural communities was rarely mentioned. Providers said they rarely met pregnant women or mothers of young children who reported experience with discrimination in the community. "It's the custom of Cambodians to usually ask how you are doing or where you are going, regardless of their status in the community," explains a health provider (\#20) from Cheung Prey district. 
Local officials said rural households talked to each other and made connections; discriminating against a particular household was extremely rare, except for those who are belligerent and hostile. However, according to village volunteers, discrimination in recruitment for employment does occur. They said it was challenging for older women aged 35 years or above or for women seemingly poor-looking to find a job at a garment factory. "I don't know why [older women or those not good-looking] can't find a job in the factory; but those who are good-looking are always easy to get a job," says a woman village volunteer (\#36).

According to the local authorities and health providers, maltreatment of children was also rare; this was referred to as verbal, sexual or physical abuse of children. However, in Cambodia, certain acts such as name-calling, verbal rebukes or even disciplinary whipping, are not regarded as maltreatment. To the local people, maltreatment means serious abuse, such as serious beating, neglect leading to starvation, or intentional starvation.

Only one provider said she met with pregnant women or mothers of young children who reported the feeling of insecurity. A commune authority (\#34), 55 years old, of Cheung Prey district said, "The security of communities is quite good; incidents of stealing, robbery and violence decreased these days." People who are involved in conflicts may feel insecure because they do not know what might happen to them. The conflicts could be related to quarrels or disputes from the past.

\section{Challenges in addressing SDH}

Challenges in addressing SDCH are several, and they are grouped as follows: 1) prevalence of social and household adverse conditions; 2) lack of health provider training and knowledge about referral; 3) lack of clear information about locally available social support resources and services; 4) lack of effective coordination for services; and 5) lack of trust in the ability of public systems to ensure the resolution of social issues.

\section{Prevalence of adverse conditions among households of pregnant women and mothers with young children}

The high frequency and prevalence of common social problems in the communities means that health and social care institutions/facilities are overwhelmed by these problems. Poverty is a common social problem and is associated with lack of food and safe drinking water, lack of stable employment and steady incomes, and lack of decent housing for providing shelter. Solutions to these problems require sustained and coordinated actions of multiple actors and institutions and involvement of different levels of authorities, i.e., from commune authorities to district and provincial, then to a central body, such as a national council or ministry. For example, district and provincial authorities, in coordination with the Ministry of Labour or the Ministry of Social Affairs, have to negotiate with a garment factory to change policy in the recruitment of women of a certain age group or people with disabilities.

"We have many poor households in the community and they need everything, even food and water. So seeing a patient lacking even these basic commodities, as a health provider I can only give suggestions where to
Table 3 Frequency of primary health care providers meeting with pregnant women or mothers with young children who are facing social and household issues $(N=31)$

\begin{tabular}{llll}
\hline $\begin{array}{l}\text { How often did you meet with women with the following } \\
\text { conditions? }\end{array}$ & $\begin{array}{l}\text { Never/Rarely } \\
(\%)\end{array}$ & $\begin{array}{l}\text { Sometimes } \\
(\%)\end{array}$ & $\begin{array}{l}\text { Frequently } \\
(\%)\end{array}$ \\
\hline Lack of knowledge about child care & 42 & 35 & 23 \\
Lack of safe place for children to rest/sleep & 58 & 32 & 10 \\
Lack of water for children to wash & 58 & 39 & 3 \\
Lack of water for children to drink & 36 & 42 & 22 \\
Lack of food & 52 & 29 & 19 \\
Household exposed to tobacco smoke & 38 & 26 & 36 \\
Household exposed to drug use & 94 & 6 & 0 \\
Household exposed to alcohol use & 83 & 10 & 7 \\
Household experiencing violence & 71 & 29 & 0 \\
Household with no income & 26 & 35 & 39 \\
Household with no employment & 46 & 35 & 19 \\
Household experiencing discrimination & 90 & 10 & 0 \\
Household experiencing isolation & 90 & 6 & 4 \\
Household experiencing maltreatment & 87 & 10 & 3 \\
Household with insecurity & 62 & 29 & 10 \\
\hline
\end{tabular}


seek assistance," says a health provider (\#10) in Cheung Prey district.

"We continue to develop the community, for example, connecting water supplies, but we can't do everywhere. So the problem of water shortage even for drinking among remote communities still exists," according to a Commune council member (\#35).

\section{Lack of health provider training in referral for social care and local support services}

Training health providers is an activity indicating that they have a role in addressing and potentially resolving an issue that their patients are facing. A significant proportion of health providers demonstrated a lack of knowledge about where to refer women for problems related to social issues. The proportion of those who reported knowing ranged from a low of $26 \%$ with regard to problems related to discrimination, to a high of $65 \%$ with regard to problems related to depression (Table 3).

None of the health providers had received any formal training in social care and referral to local support services. While over two thirds of the health providers said they had a role in addressing the social issues, a quarter of them said they were uncertain about their role and a small fraction said they did not have a role in addressing the issue. One health provider (\#15), 25 years of age said, "I've never been trained in this but if the client looks distraught, I'd ask her why out of curiosity."

Referral guidelines exist for different health issues, but even for these situations, adherence to the guidelines was limited. In the words of a provincial health official (\#32), "Depending on the problems providers are facing, we have referral guidelines for different health issues, for maternal health, TB, malaria, etc. Some clients followed the referral only in serious cases. For social problems, it depends if some kind of referral mechanism is set up there."

For some available social services, such as drug rehabilitation, which is part of the health facilities, health providers can do more effective referral. For other social issues, such as domestic violence and lack of basic commodities such as food or shelter, providers could only provide education or counseling and refer, for example, to commune or district authority for assistance.

Referring to commune and police offices was the most common action for problems related to domestic violence, poverty, food and water shortage, lack of shelter, discrimination and unemployment. District office was cited in referral for a number of instances related to poverty and unemployment. For problems closely related to health, for example, frequent coughing, diarrhea, or drug use, health providers offered education, counseling and referral to treatment centres.

\begin{abstract}
"In this district we have two health centres with treatment services for people with drug addiction problem, and all of the health centres have providers trained in and able to address psychosocial counseling and mental health," according to a health official (\#33) from Cheung Prey district.
\end{abstract}

At the community level, all village volunteers received some form of training in social and health topics, and their role is predominantly for referral and facilitation of community activities, e.g., child vaccination, blood testing, and mobilizing and facilitating hand-outs of social assistance, for instance, from the Red Cross. However, it is often unknown whether or not a referral client has received a service.

'I'd refer as I have been told, for people to get a service or help, but it's difficult to follow up as I do many referrals and some services or assistance are not always available," says a community volunteer (\#37) in Prey Chhor district.

At the community level, referrals for social services lack formal establishment and occur on an ad hoc basis; verbal referral is the norm, with lots of uncertainty in getting the services or help. A district official (\#33) said, "Health matters aside, there is no formal referral mechanism for other social matters, but simple verbal suggestion where to find help. And we sometimes hear back from commune or other providers if help is provided."

Commune council members were clear that health providers had a role in addressing social issues, since many of the health problems come from the lack of social infrastructures, poverty and lack of awareness and prevention. "Health problems are social problems, for example, diarrheal diseases, drug use and child diseases like measles are caused by drinking bad water, not knowing about consequence of drug use or not bringing children for vaccination," explained a commune council member (\#35), aged 59 years, in Cheung Prey district.

\section{Lack of clear information about available social care and local support services}

A major reason for health providers to not refer or to do referral only for matters they are familiar with was because they did not have clear information about available social 
support services. In the two districts, mapping of social services had not been done and there is no public information on a card or leaflet about where to get a social service. Health officials indicate that most midwives in the two health districts had received training on genderbased violence (GBV) and provider's roles in assisting GBV survivors and in referral for psychological counseling and drug rehabilitation. Referral lines have been established for certain social problems such as substance abuse and GBV. But for other social matters, commune and district offices are the common places referred to.

"Every social problems converge at the commune office, and people know that. Even health providers refer people here although they know we can't resolve all the cases," says a woman commune councilor (\#34).

\section{Lack of resources and coordination for local social support services}

A major bottleneck for addressing the lack of social support services is the lack of resources and coordination at different levels of authorities, including financial and human resources. While multisectoral coordination bodies exist at district and provincial levels, their functioning and effectiveness in coordinating assistances for social matters are limited, largely due to the lack of resources.

"When we know a case of domestic violence, we report to the commune office, the perpetrator is apprehended and educated and asked to sign a pledge. This seems to reduce frequency and incidence of violence," explains a district health official (\#32) in Prey Chhor.

"We are a developing nation and our resources are limited. We know what we need and what to do, but without adequate resources, like budget and manpower, there is so much we can do, and this applies to all services and sectors. For example, we need irrigation, good water connection, people with a job, child care centres, but we can't get all these at once," says a commune council member (\#35).

\section{Lack of trust in public social services}

One of the challenges in addressing SDCH is the lack of public trust in social services. This is due to the bad experience of not receiving a service when needed, or people being dissatisfied with the level and quality of public services. Rumours and bad reputation spread fast in the community of close-knit families and neighbours, and that damages the image of public services and turns people away. They would not bother to ask for or go to a public facility. Restoring public trust is difficult and needs time and proof of effectiveness.

"We have many people seeking public assistances for instance to get jobs or social assistance, but some were unsuccessful, so some people just stop going for them [these public services] and cope with the problems themselves," says a woman village volunteer (\#36).

"For health services, we seemed to be doing well, and people seek our services, but for other social issues, it rests with local authorities. When cases referred to them have poor outcomes, people just stop going," says a health district official (\#32).

\section{Opportunities for addressing SDCH}

Some of the challenges presented above could be turned into opportunities for improving interventions on SDCH. The existing administrations and mechanisms, including subnational structures, referral pathways and coordination bodies already in place, could be leveraged to facilitate actions to address SDH.

Health providers, commune, district and provincial officials cited a number of opportunities for improving addressing of SDH: mapping and dissemination of information about available public services in the districts to the public and public institutions, traditional practice of inquiry, training frontline primary health care providers about available public services and referral to them, improving the functioning of subnational coordination bodies at district and provincial levels, and improving accountability of public service institutions through evidence.

Mapping and compiling information about available services in the districts were cited as essential activities for addressing SDH. "Currently we have a limited number of social services available in the district, for example, drug rehab and GBV. For other social matters, I simply refer to commune or 
district office as there is no information where to refer to," says a health provider (\#16).

Traditional practices of social inquiry could also be leveraged and promoted among primary health care providers. For reasons of stigma or fear, some women are afraid to share their worries or problems and are willing to speak up only when they are asked. A health provider (\#30), aged 26 years old, said, "Usually women raise other [medical] problems they face when we suspect other [social] conditions and ask them; and it seems there are several big problems beyond our capacity."

Training primary health care providers about available social support services and how to refer people in need was cited as part of the essential package of an intervention addressing SDH. "We have been trained to handle GBV cases and know where to refer to for instance mental health counseling or forensic service. Referral is part of the training in a particular social service, without training, we don't know our role or where to refer cases," explains a health provider (\#22).

Interviewed officials pointed to the existing structures and mechanisms in place, such as the GBV working group and the women and children committee, which they said, could be leveraged and improved. "We have coordinating bodies at district and provincial levels to help to resolve social issues. These bodies meet regularly and review and discuss the problems......so far we do that though not so regularly due to reason of time and many other urgent issues, and often solutions need resources, for instance connecting water supplies," says a district official (\#33).

Resourcing was raised as a major factor in improving SDH, and it was a tough issue to tackle because of limited government budgets and resource allocation. "I know our resources are scarce and limited, but if the district can show results [to higher authorities] from budget use, they might be able to ask for more the next time round," said a health official (\#32).

\section{Discussion}

This study examined challenges and opportunities in addressing social determinants of child health in two rural districts in Cambodia. Social conditions and living environments in the districts are already indicative of the need for greater social care and local support services. Although considered rural, the districts are close to Phnom Penh, the capital city, located on a main national road and have seen rapid development in the last decade. Some of the indicators related to infrastructures could be better than many far-away districts. Yet, on some other social indicators, such as sanitation, households headed by women, primary occupations of the population, number of orphans and people with disabilities, and incidences of violence, the districts are quite similar to the rest of the country.
The situation of the districts may have changed a great deal, in terms of employment and improved livelihood given the increase in garment factories. However, changes in the lives of people, especially those living far from the main roads, may be limited at best. The inhabitants often lack skills and knowledge to benefit from new developments in the districts and mostly depend on manual labour jobs which have become scarce in their areas. Despite economic growth experienced in the last 2 decades, economic pressure and poverty remain the main sources of mental health problems in Cambodia (Jarl et al. 2015).

While new investments in garment factories bring jobs and improve the economy, there are new concerns associated with urban migration and the adverse effects on the health of infants and children whose mothers are employed in garment factories and the mental and general health conditions of migrant workers. Infants of migrant mothers are likely to experience a lack of care and reduced rates of breastfeeding (Jameel et al. 2019). Pressured to make ends meet, migrant workers are constantly worried and likely to develop mental health problems (Meyer et al. 2014).

The challenges in addressing SDCH identified in this study are important for health and social policy interventions because of the interlinks between health and social sectors. Along with these challenges, opportunities for addressing these were also identified. It is apparent that the absence of clear public information about available social services and how to access local supports is among the major hurdles for referral. Compiling and disseminating information about available social services in the districts are logical interventions to address the need. The material will benefit the public as well as health providers. Training health providers to use information material, do routine case finding and refer clients to appropriate services have been known not only to increase the acceptance of the role of SDH among providers but also to help them gain satisfaction from their jobs (Buys and Somerall 2018). Considerations of client characteristics and service needs and understanding of the complexity of referral systems are essential to ensure successful referrals (Bajaria et al. 2020). In this context, along with the training, a simple clinical support tool such as that developed by the CLEAR Collaboration (https://www.mcgill.ca/clear/download\#Kmer) could be modified and simplified to be culturally appropriate for Cambodian primary health care providers to begin to ask about and address the SDCH (Naz et al. 2016).

The model of gender-based violence intervention in Cambodia seems relevant to this study. Knowledge and awareness about existing services and referral mechanisms are essential parts of successful multisectoral interventions on GBV. Toward this end, a compilation of social services existing in the district or province is essential and should be disseminated to all relevant service providers (Coffey 2017). Coordination of service providers and referral system is 
established to facilitate identification of needs and access to different services, such as psychosocial and mental health support, economic needs, shelter, legal support, and/or health services to treat injuries. Cambodia has established several referral systems in the health sector which are working (Bell et al. 2015; Le et al. 2018; Nakahara et al. 2010). The experience can inform referral pathways/mechanisms for specific social problems which are agreed on and endorsed by relevant subnational authorities and social service providers. This should be accompanied with training of primary health care providers, provision of social inquiry tools, and dissemination of information about different services and referral pathways (Belfiore et al. 2018; O'Brien et al. 2019). The multisectoral coordination mechanisms at provincial and district levels are helpful for sharing information and ensuring social problems are brought up to the competent authorities. Improving the effectiveness of the coordination mechanisms and adequately resourcing them should be promoted.

The experience of providers documented in this study suggests that social problems are commonplace in the Cambodian rural community, and they are mostly related to poverty, lack of food and drinking water, tobacco and alcohol use, violence and lack of employment. Causes of poverty are also changing and currently predominantly related to unemployment, landlessness, illnesses, debts or a combination of these (Meessen et al. 2006; Zimmer 2008). Over a third of Cambodian households were in debt; Cambodian households on average have outstanding loans of approximately USD2300 in 2017 and the amount of debt had increased three folds since 2013 (MOP 2018); indebtedness has become a new worrying trend affecting psychological and mental health.

A number of social interventions for people living in poverty are active in the country. Cambodia administers an ID poor scheme whereby the poor are identified and issued an ID poor card and they use the card to access and use public health services for free and receive government allowances depending on the level of poverty they are identified with (Annear 2010; Kaba et al. 2018). Recently amid the COVID-19 worries caused by the pandemic, the resultant economic downturn and job losses, the social protection scheme funded by the Cambodian government had implemented cash transfer for over two million poor and vulnerable populations (NSPC 2020). Cambodian Red Cross offers temporary relief assistance, such as food and living commodities (CRC 2017). Other assistance mostly in charity forms and on an ad hoc basis comes from private donations and high-ranking government officials. However, these assistances are meant for temporary relief. Unless there are effectively sustaining social development initiatives, many Cambodians, especially rural populations, will continue to be deprived of development benefits and to live in the shadow of poverty.

\section{Limitations}

The study had a number of limitations. First, answers from a number of respondents suggested problems with the Khmer translation of the interview guide questions from the original English which were subject to different interpretations. For example, people may have different understandings of what is defined as "a safe place for children," "water for drinking," or "child maltreatment," considering the different cultures and understanding of contexts. Despite these problems, most answers suggested mainstream understanding of the questions. Second, the purposive sampling of providers and the small sample of districts included in the study mean that the results of the study are limited to the study districts. However, the results are also suggestive of the country's state of affairs, given that Cambodia is largely a rural and agrarian economy. Third, the data from the district 3-year revolving development plans are likely to be biased to the positive side as these plans were made by local district officials, and the methods used in the data collection were not explained; there was a general bias among local officials to "paint rosy pictures" of progress in their jurisdictions.

\section{Conclusion}

A wide range of adverse social and household conditions affect child health. Poverty is still a problem; there remain households that go without basic needs such as food and water. The economic growth in Cambodia has enabled the development of rural areas, but it also brings other problems, such as land loss, indebtedness, and economic pressure. Addressing SDCH requires broad and coordinated efforts of stakeholders from multiple sectors. It is important to recognize and leverage the existing structures and mechanisms to facilitate and/or address social and health care issues. Training frontline primary health care providers and providing them with adequate information about referral and available social services and local resources in the community are among the prerequisites in this endeavour and add to strengthening human resources for health. Nevertheless, improving social care services and infrastructures requires strong coordination, planning and adequate resource allocation.

Acknowledgements The study was part of a maternal and newborn care improvement collaborative project between the University of Health Sciences (UHS) and the Department of Family Medicine of McGill University that was funded by Grand Challenges Canada. The authors gratefully acknowledge the contributions of faculties and staff members of UHS and McGill University in the coordination and administration of funding. The authors express thanks for the inputs and opinions of 
officials of the Provincial Health Department and District Offices and participants of the study.

Authors' contributions Keovathanak Khim designed the study and tools, collected and analyzed data and wrote the manuscript. Anne Andermann contributed to the study design and manuscript writing.

\section{Compliance with ethical standards}

The study was approved by Cambodia's National Ethics Committee for Health Research and McGill University's Faculty of Medicine Institutional Review Board.

Conflict of interest The authors declare that they have no conflict of interest.

Disclaimer The opinions expressed herein are the authors' and do not necessarily reflect the views of McGill University, University of Health Sciences or Grand Challenges Canada.

\section{References}

Andermann, A., \& CLEAR Collaboration. (2016). Taking action on the social determinants of health in clinical practice: a framework for health professionals. CMAJ, 188(17-18), E474-E483. https://doi. org/10.1503/cmaj.160177.

Annear, P. L. (2010). A comprehensive review of the literature of health equity funds in Cambodia. Melbourne: Nossal Institute for Global Health, The University of Melbourne.

Annear, P. L., Tayu Lee, J., Khim, K., Ir, P., Moscoe, E., Jordanwood, T., Bossert, T., Nachtnebel, M., Lo, V. (2019). Protecting the poor? Impact of the national health equity fund on utilization of government health services in Cambodia, 2006-2013. BMJ Global Health, 4(6), e001679.

Bajaria, S., Abdul, R., Exavery, A., Minja, E., Charles, J., Mtenga, S., et al. (2020). Programmatic determinants of successful referral to health and social services for orphans and vulnerable children: a longitudinal study in Tanzania. PLoS One, 15(9), e0239163. https://doi.org/10.1371/journal.pone.0239163.

Belfiore, M. N., Blinka, M. D., BrintzenhofeSzoc, K., \& Shields, J. (2018). Screening, brief intervention, and referral to treatment (SBIRT) curriculum integration and sustainability: social work and nursing faculty perspectives. Substance Abuse, 39(2), 255-261. https://doi.org/10.1080/08897077.2017.1377672.

Bell, C. A., Ilomaki, J., Pichenda, K., Duncan, G. J., \& Saini, B. (2015). Referral of tuberculosis symptomatic clients from private pharmacies to public sector clinics for diagnosis and treatment in Cambodia. Journal of Evaluation in Clinical Practice, 21(2), 285-291. https:// doi.org/10.1111/jep.12306.

Bell, K., Corbacho, B., Ronaldson, S., Richardson, G., Torgerson, D., Robling, M., \& Building Blocks trial group. (2018). The impact of pre and perinatal lifestyle factors on child long term health and social outcomes: a systematic review. Health Economics Review, 8(1), 2. https://doi.org/10.1186/s13561-018-0186-6.

Bennett, S., Glandon, D., \& Rasanathan, K. (2018). Governing multisectoral action for health in low-income and middle-income countries: unpacking the problem and rising to the challenge. $B M J$ Global Health, 3(Suppl 4), e000880. https://doi.org/10.1136/bmjgh2018-000880.

Buys, K. C., \& Somerall, D. (2018). Social determinants of health screening and referral: innovation in graduate nursing education. The
Journal of Nursing Education, 57(9), 571-572. https://doi.org/10. 3928/01484834-20180815-13.

Charles, M. (2006). HIV epidemic in Cambodia, one of the poorest countries in Southeast Asia: a success story. Expert Review of Anti-Infective Therapy, 4(1), 1-4. https://doi.org/10.1586/14787210.4.1.1.

Coffey, I. D. (2017). Ending violence against women in Cambodia 2012 2017. Phnom Penh: Coffey International Development.

CRC. (2017). Cambodian Red Cross annual report 2016. Phnom Penh: Cambodian Red Cross.

CSDH. (2008). Closing the gap in a generation: Health equity through action on the social determinants of health. Final report on the Commission on the Social Determinants of Health. Geneva: World Health Organization.

Dahlgren, G., \& Whitehead, M. (1992). Politicies and strategies to promote equity in health. In Regional Office for Europe. Copenhagen: World Health Organization.

Davey Smith, G., \& Ebrahim, S. (2001). Epidemiology - is it time to call it a day? International Journal of Epidemiology, 30(1), 1-11.

Flores, G., Ir, P., Chean, R. M., O’Donnell, O., \& Van Doorslaer, E. (2011). Financial protection of patients through compensation of providers: the impact of health equity funds in Cambodia. Rotterdam: Tinbergen Institute.

Friel, S., Loring, B., Aungkasuvapala, N., Baum, F., Blaiklock, A., Chiang, T. L., et al. (2012). Policy approaches to address the social and environmental determinants of health inequity in Asia-Pacific. Asia-Pacific Journal of Public Health, 24(6), 896-914. https://doi. org $/ 10.1177 / 1010539512460569$.

Hill, A., Pallitto, C., McCleary-Sills, J., \& Garcia-Moreno, C. (2016). A systematic review and meta-analysis of intimate partner violence during pregnancy and selected birth outcomes. International Journal of Gynaecology and Obstetrics, 133(3), 269-276. https:// doi.org/10.1016/j.ijgo.2015.10.023.

Hooker, L., Ward, B., \& Verrinder, G. (2012). Domestic violence screening in maternal and child health nursing practice: a scoping review. Contemporary Nurse, 42(2), 198-215. https://doi.org/10.5172/ conu.2012.42.2.198.

Ir, P., Horemans, D., Souk, N., \& Van Damme, W. (2010). Using targeted vouchers and health equity funds to improve access to skilled birth attendants for poor women: a case study in three rural health districts in Cambodia. BMC Pregnancy and Childbirth, 10, 1. https://doi.org/ 10.1186/1471-2393-10-1.

Jameel, A., Vong, L., Hun, V., \& Morgan, A. (2019). Early childhood nutritional implications of the rise in factory employed mothers in rural Cambodia: a qualitative study. Maternal and Child Health Journal, 23(8), 1087-1097.

Jarl, J., Cantor-Graae, E., Chak, T., Sunbaunat, K., \& Larsson, C. A. (2015). Trauma and poor mental health in relation to economic status: the case of Cambodia 35 years later. PLoS One, 10(8), e0136410. https://doi.org/10.1371/journal.pone.0136410.

Kaba, M. W., Baesel, K., Poch, B., Bun, S., Cerceau, S., Bury, L., et al. (2018). IDPoor: a poverty identification programme that enables collaboration across sectors for maternal and child health in Cambodia. BMJ, 363, k4698. https://doi.org/10.1136/bmj.k4698.

Kawachi, I., \& Kennedy, B. (2002). The health of nations: why inequality is harmful to your health. New York: New Press.

Khim, K., \& Annear, L. P. (2013). Strengthening district health service management and delivery through internal contracting: lessons from pilot projects in Cambodia. Social Science \& Medicine, 96, 241249. https://doi.org/10.1016/j.socscimed.2013.02.029.

Khim, K., Ir, P., \& Annear, P. (2017). Factors driving change in the design, implementation and scaling-up of contracting for health service delivery in Cambodia 1997-2015. Health Systems and Reform, 3(2). https://doi.org/10.1080/23288604.2017.1291217.

Krantz, G. (2002). Violence against women: A global public health issue! Journal of Epidemiology and Community Health, 56, 242-243. 
Krieger, N. A. (2001). Theories for social epidemiology in the 21st century: an eco-social perspective. International Journal of Epidemiology, 30, 668-677.

Kuo, A. A., Shetgiri, R., Guerrero, A. D., Barreto, P. M., Perez, V. H., Fond, K., \& Slusser, W. (2011). A public health approach to pediatric residency education: responding to social determinants of health. Journal of Graduate Medical Education, 3(2), 217-223. https://doi.org/10.4300/JGME-D-10-00150.1.

Le, G., Heng, M., Nou, K., So, P., \& Ensor, T. (2018). Can positive inquiry strengthen obstetric referral systems in Cambodia? The International Journal of Health Planning and Management, 33(1), e89-e104. https://doi.org/10.1002/hpm.2385.

Lynch, J. W., et al. (2000). Income inequality and mortality: importance to health of individual income psychosocial environment, or material conditions. BMJ, 320, 1220-1224.

Marmot, M., \& Wilkinson, R. G. (2000). Social determinants of health. Oxford: Oxford University Press.

Meessen, B., Van Damme, W., Tashobya, C. K., \& Tibouti, A. (2006). Poverty and user fees for public health care in low-income countries: lessons from Uganda and Cambodia. Lancet, 368(9554), 2253 2257. https://doi.org/10.1016/S0140-6736(06)69899-1.

Meyer, S. R., Robinson, W. C., Chhim, S., \& Bass, J. K. (2014). Labor migration and mental health in Cambodia: a qualitative study. The Journal of Nervous and Mental Disease, 202(3), 200-208. https:// doi.org/10.1097/NMD.0000000000000101.

MOH, \& MOWA. (2016). Training manual for minimum basic counseling on gender based violence. Phnom Penh: Ministry of Women's Affairs (MOWA).

Mohammad, E. T., Shapiro, E. R., Wainwright, L. D., \& Carter, A. S. (2015). Impacts of family and community violence exposure on child coping and mental health. Journal of Abnormal Child Psychology, 43(2), 203-215. https://doi.org/10.1007/s10802-0149889-2.

MOP. (2018). Cambodia Socio-Economic Survey 2017. Phnom Penh: National Institute of Statistics, Ministry of Planning.

MOSVY. (2014). National Disability Strategic Plan 2014-2018. Phnom Penh: Ministry of Social Affairs, Veterans and Youth Rehabilitation.

MOWA. (2014). National Action Plan to Prevent Violence Against Women (NAPVAW) 2014-2018. Phnom Penh: Ministry of Women's Affairs.

Nakahara, S., Saint, S., Sann, S., Ichikawa, M., Kimura, A., Eng, L., \& Yoshida, K. (2010). Exploring referral systems for injured patients in low-income countries: a case study from Cambodia. Health Policy and Planning, 25(4), 319-327. https://doi.org/10.1093/ heapol/czp063.

National Academies of Sciences, E., and Medicine. (2016). A framework for educating health professionals to address the social determinants of health. Washington: The National Academies Press.

Navarro, V. (1977). Social class, political power, and the state and their implications in medicine. International Journal of Health Services, 7(2), 255-292.

Naz, A., Rosenberg, E., Andersson, N., Labonte, R., Andermann, A., \& CLEAR Collaboration. (2016). Health workers who ask about social determinants of health are more likely to report helping patients: mixed-methods study. Canadian Family Physician, 62(11), e684 e693.

NCDD. (2015). Implementation of social accountability framework. Phnom Penh: Ministry of Interior.

NIS. DGH. ICF International. (2015). Cambodia demographic and health survey 2014. Phnom Penh: Ministry of Planning, Ministry of Health, ICF International.

Noirhomme, M., Meessen, B., Griffiths, F., Ir, P., Jacobs, B., Thor, R., et al. (2007). Improving access to hospital care for the poor: comparative analysis of four health equity funds in Cambodia. Health Policy and Planning, 22(4), 246-262. https://doi.org/10. 1093/heapol/czm015.

NSPC. (2020). Social assistances by Cambodian government. https://www. nspc.gov.kh/social-assistance-cambodia. Accessed 1 Sept 2020.

O’Brien, K. H. M., Putney, J. M., Collin, C. R., Halmo, R. S., \& Cadet, T. J. (2019). Optimizing screening, brief intervention, and referral to treatment (SBIRT) training for nurses and social workers: Testing the added effect of online patient simulation. Subst Abus, 40(4), 484-488. https:// doi.org/10.1080/08897077.2019.1576087.

Phalla, T., Leng, H. B., Mills, S., Bennett, A., Wienrawee, P., Gorbach, P., \& Chin, J. (1998). HIV and STD epidemiology, risk behaviors, and prevention and care response in Cambodia. AIDS, 12 Suppl B, S11-18.

Raphael, D. (2004). Social determinants of health: Canadian perspectives. Toronto: Canadian Scholars' Press.

Rasanathan, K., Bennett, S., Atkins, V., Beschel, R., Carrasquilla, G., Charles, J., . . Z Zaidi, S. (2017). Governing multisectoral action for health in low- and middle-income countries. PLoS Medicine, 14(4), e1002285. https://doi.org/10.1371/journal.pmed.1002285.

Saha, S., \& Gerdtham, U. G. (2013). Cost of illness studies on reproductive, maternal, newborn, and child health: A systematic literature review. Health Economics Review, 3(1), 24. https://doi.org/10. 1186/2191-1991-3-24

Soeung, S. C., Grundy, J., Sokhom, H., Blanc, D. C., \& Thor, R. (2012). The social determinants of health and health service access: an in depth study in four poor communities in Phnom Penh Cambodia. International Journal for Equity in Health, 11, 46. https://doi.org/ 10.1186/1475-9276-11-46.

Tong, A., Sainsbury, P., \& Craig, J. (2007). Consolidated criteria for reporting qualitative research (COREQ): a 32-item checklist for interviews and focus groups. International Journal for Quality in Health Care, 19(6), 349-357. https://doi.org/10.1093/intqhe/ mzm042.

Unicef, UNDP, \& WHO. (2018). Disability rights initiative CAMBODIA (DRIC): Final Programme Narrative Report (December 2013 March 2018). Phnom Penh: United Nations Children's Fund (Unicef), United Nations Development Programme (UNDP), World Health Organization (WHO).

Van Damme, W., Ir, P., Horemanns, D., \& Narin, S. (2008). Improving access to safe delivery for poor pregnant women: a case study of vouchers plus health equity funds in three health districts in Cambodia. Studies in Health Services Organisation and Policies, 24, 225-253.

World Bank. (2019). Country data, Cambodia. https://data.worldbank. org/country/cambodia. Accessed 2 Feb 2019.

Wilson, J. (1983). Historical materialism. In J. Wilson (Ed.), Social theory. Englewood Cliffs: Prentice Hall.

World Bank. (2019). The World Bank in Cambodia. https://www. worldbank.org/en/country/cambodia. Accessed 22 Nov 2019.

World Health Organization. (1986). Ottawa charter for health promotion. European Office. Geneva: WHO.

Ziaei, S., Naved, R. T., \& Ekstrom, E. C. (2014). Women's exposure to intimate partner violence and child malnutrition: findings from demographic and health surveys in Bangladesh. Maternal \& Child Nutrition, 10(3), 347-359. https://doi.org/10.1111/j.1740-8709. 2012.00432.x.

Zimmer, Z. (2008). Poverty, wealth inequality and health among older adults in rural Cambodia. Social Science \& Medicine, 66(1), 57-71. https://doi.org/10.1016/j.socscimed.2007.08.032.

Publisher's note Springer Nature remains neutral with regard to jurisdictional claims in published maps and institutional affiliations. 